\title{
A case of pediatric perioperative anaphylaxis to neuromuscular agents and its management
}

\author{
Marat Ospanov $^{1}$, Yuri Olkhovik ${ }^{1}$, Zhazira Manaibekova ${ }^{2}$, Zhenis Sakuov ${ }^{1}$, Arman Kozhakhmetov $^{3}$ \\ ${ }^{\prime}$ Department of Pediatric Surgery, National Research Mother and Child Center, Nur-Sultan, Kazakhstan \\ ${ }^{2}$ Department of Pediatric Anesthesiology, Reanimation and Intensive Care, National Research Mother and Child Center, Nur-Sultan, Kazakhstan \\ ${ }^{3}$ Department of Medicine, School of Medicine, Nazarbayev University, Nur-Sultan, Kazakhstan
}

Received: 2021-06-17.

Accepted: 2021-12-26

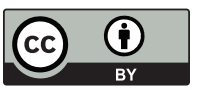

This work is licensed under a Creative Commons Attribution 4.0 International License

\section{J Clin Med Kaz 2022; 19(1):77-79}

Corresponding author:

Arman Kozhakhmetov.

Email: a.kozhakhmetov@nu.edu.kz

ORCID: 0000-0001-6462-5171

\section{Abstract}

Background: Perioperative anaphylaxis is one of the most challenging complications in anesthesiology. The key role is to determine the causative agent of the reaction. Neuromuscular agents are ones of the most common causes of anaphylaxis. Skin tests including prick and intradermal reaction tests are gold standard for definite diagnosis.

Case presentation: We present a case of a child undergone several operations due to congenital esophageal atresia. Later on, attempts to perform a definitive repair failed because of perioperative anaphylaxis. Allergic skin tests were performed and rocuronium was found to be positive and atracurium - negative. The operation was successfully performed with atracurium.

Conclusion: In patients who have gone through multiple surgeries the risk of anaphylaxis development is higher. The most common cause is considered to be neuromuscular blocking agents. In our case, after thorough examination of the anesthesiology cards, rocuronium and pipecuronium were defined as causes of anaphylaxis in our patient, so the surgery was done with atracurium which had been seen negative on a skin prick test. Eventually, the surgical procedure was performed successfully.

Key words: peroperative anaphylaxis, NMBA, atracurium

\section{Introduction}

Perioperative anaphylaxis is one of the most challenging complications in anesthesiology. The key role is to determine the causative agent of the reaction. Neuromuscular blocking agents (NMBA) are ones of the most common causes of anaphylaxis. Skin tests including prick and intradermal reaction tests are gold standard to define the allergen. We present a case of a child with a congenital esophageal atresia, in which several attempts to repair failed because of perioperative anaphylaxis. Allergic skin tests were performed and rocuronium was found to be positive and atracurium - negative. Eventually, the surgery was successfully performed with atracurium.

\section{Case presentation}

An infant was born on 24.11.2016 with esophageal atresia with trachea-esophageal fistula. On the second day of life the right thoracotomy with lower tracheaesophageal fistula ligation was done, however, primary repair was not feasible. Because of this feeding gastrostomy and esophagostomy was created.

Due to gastrostomy and esophagostomy dysfunction their reconstruction was done on the second year of life without any perioperative complications in UMC NRMCC Astana city.

2 attempts to perform esophageal reconstruction with a modified colonic interposition graft as definitive treatment failed because of perioperative anaphylactic shock developed during the procedures.

Both surgical procedures were performed under general anesthesia induced with $50 \mathrm{mg}$ of propofol, 30 $\mu \mathrm{g}$ of fentanyl and $10 \mathrm{mg}$ of Suxamethonium chloride. Tracheal intubation was performed uneventfully. Sevoflurane was used for general anesthesia.

In the first procedure on the 40th minute after anesthesia induction $10 \mathrm{mg}$ of Rocuronium was administered for myorelaxation. In 15 minutes increase in airway pressure up to $40 \mathrm{~cm} \mathrm{H} 2 \mathrm{O}$, reduction in blood pressure, skin flushing, and edema on his face and groin 
were confirmed. Heart rate was $90 \mathrm{bpm}$ or more and systolic arterial blood pressure fell to less than $60 \mathrm{mmHg}$. Anaphylaxis was suspected, and after appropriate treatment signs of allergic reaction resolved. Decision was made to postpone the surgery in order to define the cause of the reaction.

In the second procedure based on the results of skin prick tests the tactic of anesthesia induction and maintenance had been changed. However, in 30 minutes after Pipecuronium administration signs of anaphylactic shock were observed again. Of note, fentanyl was continuously infused during the both procedures.

In November 2020 the child was admitted to the National Research Center for Maternal and Child Health for elective surgery. Considering previous reactions, skin prick tests were performed to check all the drugs which would be used during the surgery (Table 1) (Figure 1).

\section{Table 1}

Results of skin prick tests.

\begin{tabular}{|l|l|}
\hline Agent & Positive/negative result. \\
\hline Rocuronium & + \\
\hline Pipecuronium & + \\
\hline Atracurium & - \\
\hline Suxamethonium chloride & - \\
\hline Propofol & - \\
\hline Fentanyl & + - \\
\hline Ceftriaxon & - \\
\hline Iodine & - \\
\hline Morphine & + - (was considered as false positive \\
& due to local irritating reaction). \\
\hline Tramadol & - \\
\hline Trimeperidine & - \\
\hline Ketamine & - \\
\hline &
\end{tabular}

Figure 1 - Skin prick tests

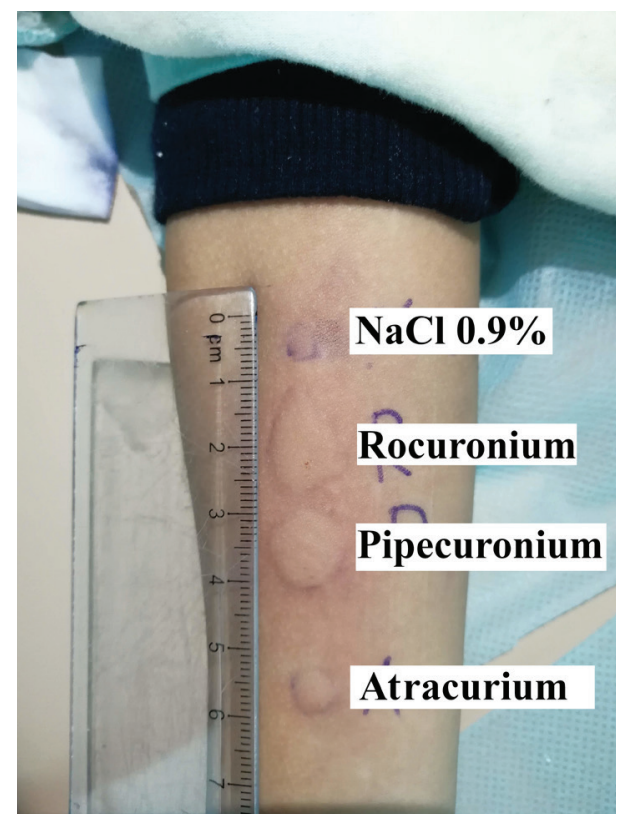

Based on these results the decision was made to perform the procedure using atracurium for myorelaxation. Also adequate premedication with corticosteroids and $\mathrm{H} 1$ blockers was done.

The operation - Esophageal reconstruction with a modified colonic interposition graft - was started under general anesthesia with propofol, fentanyl, and atracurium and was maintained with sevoflurane, atracurium (continuous infusion), ketamine and intermittent fentanyl. 2 central venous catheters, 1 peripheral venous catheter and 1 central arterial catheter were placed. Invasive arterial pressure measurement with intraarterial catheter was established and central venous pressure was measured through the central venous line. The procedure was started in 1 hour after the induction of general anesthesia. The duration of the general anesthesia was 6 hours 9 minutes, surgery itself - 5 hours 10 minutes. The vital signs were in normal range during the general anesthesia. Surgery was completed uneventfully.

No further anaphylactic reaction or other complications occurred, and the child was extubated the next day.

\section{Discussion}

The perioperative anaphylaxis is a rare yet life-threatening situation leading to multisystem failure which may happen during any surgical procedure. The incidence rate is 1:10 000 to 1:20 000 cases [1]. The mechanism is typically an IgE-mediated (type 1) hypersensitivity reaction which involves release of mast cell- and basophil-derived mediators into the circulation after re-exposure to a specific antigen [2].

The anaphylactic reaction may occur after administration of any drug. Therefore, because during surgery multiple drugs are administered it can be difficult to define the exact cause of this reaction. In order to define the trigger of hypersensitivity reaction thorough analysis of the preceding anesthesiology cards is crucial. Since it was not an emergency surgery, it was suspended until definite identification of the antigen for anaphylaxis.

Among various methods for diagnostic investigation, in vivo skin tests including prick and intradermal reaction tests remain the gold standard for detection of IgE-dependent allergies [3]; these tests are best done after a delay of 4 to 6 weeks. According to the Kazakhstan clinical guideline [4] the evaluation includes a clinical history, review of the records, analysis of laboratory tests obtained at the time, skin testing or in vitro serum-specific IgE testing, and provocation test, which are useful in the case when other methods failed.

Generally, NMBAs are considered to be one of the main causes of perioperative anaphylaxis [5]. An IgE-mediated response is due to the quaternary ammonium (NH4+) structures that represents the main antigenic epitope of NMBAs [6]. We detected rocuronium and pipecuronium to be positive on skin prick tests 8 months after the onset of anaphylaxis, therefore, we were able to recognize them as possible causes of the reaction. Also we suspected fentanyl as a causative agent of the anaphylaxis, however, fentanyl is rarely a cause of true anaphylaxis [7] and our skin tests excluded fentanyl from the list.

Among NMBAs atracurium, cis-atracurium, and pancuronium are associated with a lower allergic risk [8]. During our evaluation, atracurium was confirmed negative after performing the skin prick tests. The surgery was successfully performed using atracurium for myorelaxation.

In the case of perioperative anaphylaxis NMBAs should be considered one of the first causative agents. If an allergic test to NMBA is positive other low allergy risk NMBAs may be considered. Furthermore, it is important to evaluate all cases of perioperative anaphylaxis with a multidisciplinary approach.

During our work-up regarding causative agents of anaphylaxis other potential causes were excluded. Antibiotics are often administered prior or during anesthesia and they are an increasing cause of perioperative anaphylaxis. Based on negative skin allergic tests, ceftriaxon was used. Another 
common cause of allergic reaction is latex. However, we used latex-free equipment during the surgery. Povidone-iodine, said to be a much rarer cause of anaphylaxis, had also been excluded as a causative agent. Less common causes of perioperative anaphylaxis such as opioids and hypnotic agents were shown to be negative after the skin prick test.

\section{Conclusion}

In patients who have gone through multiple surgeries the risk of anaphylaxis development is higher. The most common cause is considered to be neuromuscular blocking agents. In our case, after thorough examination of the anesthesiology cards, rocuronium and pipecuronium were defined as causes of anaphylaxis in our patient, so the surgery was done with atracurium which had been seen negative on a skin prick test. Eventually, the surgical procedure was performed successfully.

Disclosures: There is no conflict of interest for all authors.

Acknowledgements: None.

Funding: None.

Patient informed consent: Obtained.

\section{References}

1. Fisher MM, Baldo BA. The incidence and clinical features of anaphylactic reactions during anesthesia in Australia. Ann Fr Anesth Reanim. 1993; 12(2):97-104. https://doi.org/10.1016/S0750-7658(05)81016-0

2. Castells MC, Horan RH, Ewan PW. Anaphylaxis. In: Holgate ST, Church MK, Lichtenstein LM, editors. Allergy. 2nd ed. London: Mosby; 2001. 163-73 pp. https://www.ncbi.nlm.nih.gov/pmc/articles/PMC3209676/

3. Mertes PM, Malinovsky JM, Jouffroy L, Working Group of the SFAR and SFA, Aberer W, Terreehorst I, et al. Reducing the risk of anaphylaxis during anesthesia. 2011 updated guidelines for clinical practice. Investig Allergol Clin. Immunol. 2011;21:442-53. https:// pubmed.ncbi.nlm.nih.gov/21995177

4. The Kazakhstan clinical guideline on diagnosis and treatment of drug hypersensitivity reaction (drug allergy) with different clinical manifestations. №121; 2020.

5. Shrikant M. Anaphylaxis during the perioperative period. Anesth Essays Res. 2012;6(2):124-133. https://doi.org/10.4103/02591162.108286

6. Didier A. Role of the quaternary ammonium ion determinants in allergy to muscle relaxants. J Allergy Clin Immunol. 1987;79:578584. https://doi.org/10.1016/S0091-6749(87)80152-5

7. Hepner DL, Castells MC. Anaphylaxis during the perioperative period. Anesth Analg. 2003;97:1381-95. https://doi.org/10.1213/01. ANE.0000082993.84883.7D

8. Mertes PM, Volcheck GW. Anaphylaxis to neuromuscular blocking drugs: all neuromuscular blocking drugs are not the same. Anesthesiology. 2015;122:5-7. https://doi.org/10.1097/ALN.0000000000000516 